\title{
PENINGKATAN KETERAMPILAN MENGAJAR MAHASISWA PENDIDIKAN TEKNIK SIPIL DAN PERENCANAAN, FT, UNY MELALUI METODE DRILL BERBASIS KOMUNIKASI VERBAL-NON VERBAL
}

\author{
Galeh Nur Indriatno Putra Pratama ${ }^{1}$, Suparman $^{2}$ \\ ${ }^{1,2}$ Pendidikan Teknik Sipil dan Perencanaan, FT, UNY \\ Email: galeh@uny.ac.id
}

\begin{abstract}
This study aims to investigate whether the drill method (verbal and non-verbal communication skill drill) is able to improve the basic teaching skills in microteaching context. This is classroom action research. The population consisted of students majoring in Civil Engineering and Planning Education Department, Faculty of Engineering, Yogyakarta State University who were taking microteaching practice course at 2019. The sample of the study was class A2 consisted of 11 students. The study was conducted in three cycles. Cycle 1 contained basic verbal communication, cycle 2 encompassed basic non-verbal communication, and cycle 3 covered both basic verbal and non-verbal communication types. Observation and skills assessment sheets were employed. The qualitative descriptive and descriptive statistics methods were then used to analyze the data.The results show that: (1) basic verbal communication skill drill in microteaching practices improves student teachers' basic microteaching skills and (2) basic non-verbal communication skill drill in microteaching practices improve student teachers' basic microteaching skills.
\end{abstract}

Keywords: drill, communication, instructional media, posters, workshop

\begin{abstract}
ABSTRAK
Tujuan kajian ini adalah untuk mengungkap bagaimana pengaruh metode drill keterampilan dasar mengajar (verbal maupun nonverbal) mampu meningkatkan keterampilan dasar mengajar terbatas pada pengajaran mikro. Kajian ini merupakan kajian tindakan kelas (classroom research). Populasi kajian ini adalah mahasiswa jurusan Pendidikan Teknik Sipil dan Perencanaan FT UNY yang sedang melaksanakan praktik pengajaran Mikro pada tahun 2019. Sampel kajian adalah kelas A2 sejumlah 11 mahasiswa. Kajian dilaksanakan selama tiga siklus. Tinjauan pertama adalah dasar komunikasi verbal, tinjauan kedua adalah dasar komunikasi non verbal, tinjauan ketiga adalah dasar komunikasi verbal dan non verbal. Observasi kegiatan dilakukan oleh peneliti dengan lembar pengamatan. Penilaian keterampilan juga menggunakan lembar penilaian keterampilan. Data dianalisis secara deskriptif kuantitatif dan kualitatif. Hasil kajian menunjukan bahwa: (1) metode drill keterampilan dasar komunikasi verbal yang diterapkan pada praktik keterampilan dasar mengajar terbatas dalam pengajaran mikro dapat meningkatkan keterampilan mengajar dasar terbatas. (2) metode drill keterampilan dasar komunikasi nonverbal yang diterapkan pada praktik keterampilan dasar mengajar terbatas dalam pengajaran mikro dapat meningkatkan keterampilan mengajar dasar terbatas.
\end{abstract}

Kata kunci: drill, komunikasi, pengajaran mikro

\section{PENDAHULUAN}

Salah satu keterampilan yang harus dimiliki oleh guru adalah keterampilan berkomunikasi. Komunikasi merupakan landasan bagi berlangsungnya suatu proses belajar mengajar yang efektif (M. Surya, 2013: 334) Pelaksanaan pembelajaran mikro yang dilaksanakan saat ini adalah terbagi dua tahap. Tahap pertama adalah latihan mengajar terbatas artinya mahasiswa dilatih hanya pada bagian pembukaan, atau penutupan atau sebagian dari inti pembelajaran seperti keterampilan menjelaskan dan sebagainya. Tahap kedua adalah latihan pembelajaran terpadu mulai dari membuka pelajaran, menyampaikan materi, melakukan interaksi, menggunakan 
bahasa, mengevaluasi, dan menutup pelajaran (panduan pengajaran mikro UNY). Kenyataan dalam pengajaran mikro sebagian mahasiswa kurang terampil berkomunikasi. Salah satu solusi untuk meningkatkan keterampilan berkomunikasi adalah perlu latihan yang berulang-ulang tentang komunikasi verbal maupun non verbal. Kedua komunikasi ini sangat penting dikembangkan untuk menunjang keterampilan guru dalam mengajar. Latihan mengajar dalam pengajaran mikro selama ini dilakukan dengan mengulangi banyak keterampilan baik dalam latihan membuka, menutup, maupun pada tahan penyampaian materi pembelajaran.

Pengulangan seperti di atas kurang efektif karena mengulangi banyak keterampilan. Dalam metode drill akan dilatihkan keterampilan yang sangat mikro seperti latihan bersuara keras dan jelas, latihan berjalan didalam kelas dan sebagainya (Pratama, 2019). Bila latihan ini dilakukan sampai benar-benar dimiliki oleh mahasiswa praktikan mikro, maka keterampilan mengajar lainnya akan lebih mudah dikembangkan.

Pengertian tentang metode drill yang disampaikan para ahli ada yang hampir sama. Berikut ini adalah pendapat mereka tentang metode drill. Nana Sudjana (1991) menyatakan bahwa metode drill adalah satu kegiatan melakukan hal yang sama, berulang-ulang secara sungguh-sungguh dengan tujuan untuk memperkuat suatu asosiasi atau menyempurnakan suatu ketrampilan agar menjadi bersifat permanen. Pratama, 2015 berpendapat ciri yang khas dari metode ini adalah kegiatan berupa pengulangan yang berkali-kali dari suatu hal yang sama.

Toto Hernawo menyatakan bahwa metode drill (latihan) disebut juga metode training, adalah suatu cara mengajar yang baik untuk menanamkan dan memelihara kebiasaan, serta untuk memperoleh suatu ketangkasan, ketepatan, kesempatan, dan keterampilan tertentu (Toto Herwano, 2017). Senada dengan pendapat di atas, Sugiyanto (1993) menjelaskan bahwa metode drill adalah metode dimana siswa melakukan gerakan-gerakan sesuai dengan apa yang diintruksikan guru dan melakukannya secara berulang-ulang. Pengulangan gerakan ini dimaksudkan agar terjadi otomatisasi gerakan. Beberapa pengertian tentang metode drill yang dikemukakan oleh ahli di atas pada dasarnya adalah sama yaitu dilakukan dengan latihan berulang-ulang untuk memperoleh keterampilan tertentu dengan harapan dapat menjadi keterampilan yang otomatis.

Komunikasi adalah proses pemindahan pengertian dalam bentuk gagasan, informasi dari seseorang ke orang lain (Handoko, 2002 : 30). Komunikasi adalah transfer makna dari satu orang ke orang lain untuk menyampaikan informasi dan gagasan. Bahkan, komunikasi itu lebih dari sekedar menanamkan makna tetapi harus juga dipahami (Robbins, 2002: 310).

Komunikasi dapat berbentuk verbal maupun non verbal. Komunikasi verbal adalah komunikasi yang mengunakan media verbal kata-kata dan lisan dalam menyampaikan pesan. Sedang komunikasi non verbal adalah komunikasi menggunakan media non verbal dalam menyampaikan pesannya seperti media wajah, mata, tubuh, sentuhan, suara, ruang, waktu, daya tarik fisik, pakaian, dan lingkungan (Budiyatna dan Ganiem, 2012:111). Komunikasi verbal efektif apabila mampu: (1) mengembangkan kesan positif sehingga komunikasi menjadi menyenangkan. (2) merangsang siswa untuk berbicara. (3) menggali pendapat. (4) 
merasakan perasaan siswa. (5) menunjukkan rasa persetujuan. (6) memberi kontak mata yang cukup. (7) membangun ikatan sehingga terjadi keakraban. (8) memberi kesan menyukai. (9) memotivasi. (10) menunjukkan suara dan bahasa tubuh lebih bersemangat. (11) menyebut nama siswa dengan cara yang baik. Sedang, komunikasi nonverbal memiliki karakteristik sebagai berikut (1) memiliki sifat berkesinambungan, (2) kaya dalam makna, (3) dapat membingungkan, menyampaikan emosi, (5) dikendalikan oleh norma, (6) terkait dengan budaya.

Buku panduan pengajaran mikro Universitas Negeri Yogyakarta (UNY) dapat dijelaskan, pengajaran mikro disebut juga praktik magang II. Kompetensi dasar dalam pengajaran mikro adalah sebagai berikut. (1) Memahami dasar-dasar Pengajaran Mikro/ Magang II, (2) Menyusun Rencana Pelaksanaan Pembelajaran, (3) Mempraktikkan keterampilan dasar mengajar terbatas, (4) Mempraktikkan keterampilan dasar mengajar terpadu, (5) Mengevaluasi praktik Pengajaran Mikro. Pengajaran mikro dilaksanakan di program studi (prodi) masing-masing fakultas oleh dosen pembimbing pengajaran mikro dan dikoordinasi oleh seorang koordinator pengajaran mikro tingkat prodi maupun fakultas. Pelaksanaan pengajaran mikro dilakukan pada semester VI.

Ada sepuluh komponen keterampilan dasar mengajar. Komponen membuka pelajaran mencakup: (1) menarik perhatian siswa, (2) memotivasi siswa, (3) memberi acuan, (4) memberi kaitan (apersepsi). komponen menutup pelajaran mencakup: (1) meninjau kembali materi yang telah dipelajari siswa, (2) mengevaluasi hasil belajar siswa, (3) membuat simpulan atau ringkasan materi, (4) memberikan tugas yang signifikan (sesuai, bermakna, dan bermanfaat).

\section{METODE}

Jenis kajian ini adalah kajian tindakan kelas. Kajian ini berupaya memperbaiki kinerja pembelajaran mikro dengan metode drill yang diterapkan dalam pengajaran mikro dalam rangka meningkatkan keterampilan dasar mengajar terbatas pada mahasiswa S1 yang akan melaksanakan praktik lapangan terpadu (PLT) di SMK. Populasi kajian ini adalah mahasiswa jurusan Pendidikan Teknik Sipil dan Perencanaan FT UNY yang mengikuti kuliah pengajaran mikro semester 7 tahun 2019. Sampel kajian adalah mahasiswa rombongan belajar kelas A2 sebanyak 11 mahasiswa yang praktis kelas ini diampu oleh tim kajian ini.

Kajian ini dilakukan sesuai dengan langkah-langkah model action research menurut Kurt Lewin yang terdiri atas empat komponen, yaitu: (1) perencanaan (planning), (2) tindakan (acting), (3) pengamatan (observing), dan (4) refleksi (reflecting). Tahapan perencanaan adalah melakukan persiapan yang akan dilaksanakan pada langkah pelaksanaan yang mencakup perencanaan silabus pembelajaran mikro, rencana program perkuliahan, dan lembar observasi. Kegiatan praktik dasar mengajar terbatas dilaksanakan sekali sebelum kegiatan drill komunikasi dimaksudkan agar diketahui kemampuan awal keterampilan komunikasi mahasiswa. Praktik dasar keterampilan mengajar terbatas dilanjutkan setelah selesai drill komunikasi. Hasil praktik dasar mengajar sesudah dan sebelum kegiatan drill komunikasi diobservasi untuk diketahui 
perubahannya. Pada tahap pelaksanaan adalah melaksanakan pembelajaran sesuai dengan tahap perencanaan. Selanjutnya, tahap observasi kegiatan belajar dilakukan pada saat pembelajaran berlangsung. Disamping observasi kegiatan, mahasiswa juga dinilai kompetensinya secara kualitatif. Tahap refleksi adalah tahap melakukan diskusi antara tim peneliti dan mahasiswa dalam rangka perbaikan pembelajaran. Data dikumpulkan dengan observasi mengunakan lembar observasi kegiatan dan lembar evaluasi pencapaian keterampilan. Data observasi kegiatan dan data pencapaian keterampilan dianalisis secara deskriptif kualitatif dan kuantitatif pada setiap kegiatan pengajaran mikro.

\section{HASIL DAN PEMBAHASAN}

Kajian ini dimulai pada kegiatan latihan dasar mengajar terbatas yaitu membuka dan menutup pelajaran. Kegiatan ini dimaksudkan untuk mengetahui kemampuan awal mahasiswa. Sebanyak 11 mahasiswa dalam kelas ini seluruhnya tampil latihan dasar mengajar terbatas dengan waktu 10 menit setiap mahasiswa. Hasil observasi dalam kegiatan ini menunjukan bahwa penampilan mahasiswa masih banyak mengalami kesulitan dalam berkomunikasi secara verbal, non verbal, dan tidak semua komponen dalam membuka dan menutup pelajaran ditampilkan.

Tinjauan pertama dilakukan pada drill keterampilan dasar komunikasi verbal dalam mengajar. Mahasiswa dilatih melakukan komunikasi secara verbal dalam mengajar selama 10 menit. Materi yang dilatihkan adalah volume suara, keluwesan berbicara, kejelasan berbicara, dan kelancaran berbicara. Dalam satu tatap muka, semua mahasiswa melakukan latihan ini diulang 2 atau 3 kali secara langsung. Hasil penilaian pada kegiatan ini adalah seperti terlihat pada tabel 1-3 di bawah ini.

Tabel 1. Penilaian Kegiatan Drill Dasar Komunikasi Verbal (Pertama)

\begin{tabular}{crrrrrr}
\hline $\begin{array}{c}\text { No Urut } \\
\text { Mahasiswa }\end{array}$ & \multicolumn{2}{c}{ Skor Keterampilan Komunikasi Verbal } & \multirow{2}{*}{ Jumlah Skor } & \multirow{2}{*}{ Rerata Skor } \\
\hline 1 & 1 & 1 & 1 & 1 & 4 & 1 \\
2 & 1 & 1 & 1 & 1 & 4 & 1 \\
3 & 1 & 1 & 1 & 1 & 4 & 1 \\
4 & 2 & 1 & 1 & 1 & 5 & 1.25 \\
5 & 2 & 2 & 2 & 2 & 8 & 2 \\
6 & 2 & 2 & 2 & 2 & 8 & 2 \\
7 & 1 & 1 & 1 & 1 & 4 & 1 \\
8 & 2 & 2 & 2 & 2 & 8 & 2 \\
9 & 2 & 2 & 1 & 1 & 6 & 1.5 \\
10 & 1 & 1 & 1 & 1 & 4 & 1 \\
11 & 1 & 1 & 1 & 1 & 4 & 1 \\
Jumlah & 16 & 15 & 14 & 14 & & \\
Rerata Skor & 1.455 & 1.364 & 1.273 & 1.273 & & 1.341 \\
\hline
\end{tabular}


Tabel 2. Penilaian Kegiatan Drill Dasar Komunikasi Verbal (Kedua)

\begin{tabular}{crrrrrr}
\hline $\begin{array}{c}\text { No Urut } \\
\text { Mahasiswa }\end{array}$ & \multicolumn{2}{c}{ Skor Keterampilan Komunikasi Verbal } & \multirow{2}{*}{ Jumlah Skor } & \multirow{2}{*}{ Rerata Skor } \\
\hline 1 & Suara & Keluwesan & Kejelasan & Kelancaran & \multirow{2}{*}{ J } \\
2 & 2 & 2 & 2 & 2 & 8 & 1.75 \\
3 & 1 & 2 & 2 & 2 & 7 & 2 \\
4 & 2 & 3 & 2 & 1 & 8 & 2 \\
5 & 2 & 3 & 2 & 1 & 8 & 2.25 \\
6 & 2 & 2 & 3 & 2 & 9 & 2.25 \\
7 & 2 & 2 & 3 & 2 & 9 & 1.5 \\
8 & 1 & 2 & 2 & 1 & 6 & 2 \\
9 & 2 & 2 & 2 & 2 & 8 & 2 \\
10 & 2 & 3 & 2 & 1 & 8 & 1.5 \\
11 & 1 & 2 & 1 & 2 & 6 & 2 \\
Jumlah & 2 & 3 & 1 & 2 & 8 & \\
Rerata Skor & 19 & 26 & 22 & 18 & & 1.932 \\
\hline
\end{tabular}

Tabel 3. Penilaian Kegiatan Drill Dasar Komunikasi Verbal (Ketiga)

\begin{tabular}{crrrrrr}
\hline $\begin{array}{c}\text { No Urut } \\
\text { Mahasiswa }\end{array}$ & \multicolumn{2}{c}{ Skor Keterampilan Komunikasi Verbal } & \multirow{2}{*}{ Jumlah Skor } & \multirow{2}{*}{ Rerata Skor } \\
\hline 1 & 2 & 4 & 4 & 4 & 14 & 3.5 \\
2 & 2 & 2 & 4 & 4 & 12 & 3 \\
3 & 3 & 4 & 3 & 4 & 14 & 3.5 \\
4 & 4 & 4 & 4 & 3 & 15 & 3.75 \\
5 & 4 & 2 & 4 & 4 & 14 & 3.5 \\
6 & 4 & 4 & 4 & 4 & 16 & 4 \\
7 & 3 & 4 & 4 & 3 & 14 & 3.5 \\
8 & 4 & 4 & 4 & 4 & 16 & 4 \\
9 & 4 & 4 & 4 & 4 & 16 & 4 \\
10 & 3 & 2 & 3 & 4 & 12 & 3 \\
11 & 4 & 4 & 3 & 4 & 15 & 3.75 \\
Jumlah & 37 & 38 & 41 & 42 & & \\
Rerata Skor & 3.364 & 3.455 & 3.727 & 3.818 & & 3.591 \\
\hline
\end{tabular}

Berdasarkan dari sajian tabel di atas (perubahan siklus I-III) pada kegiatan dasar komunikasi verbal dapat dijelaskan, dengan cara melakukan perulangan (drill) mahasiswa pengalami peningkatan penguasan kompetensi. Berdasarkan skor rerata per aspek tinjaun keterampilan terdapat peningkatan yang signifikan pada siklus ke-II hingga siklus ke-III, hal ini dikarenakan mahasiswa perlu melakukan pembelajaran berulang dan mencoba dengan cara metode drill untuk mendapatkan skill yang sesuai dengan pembentukan kompetensi. Secara lengkap peningkatan per siklus disajikan dalam grafik berikut. 


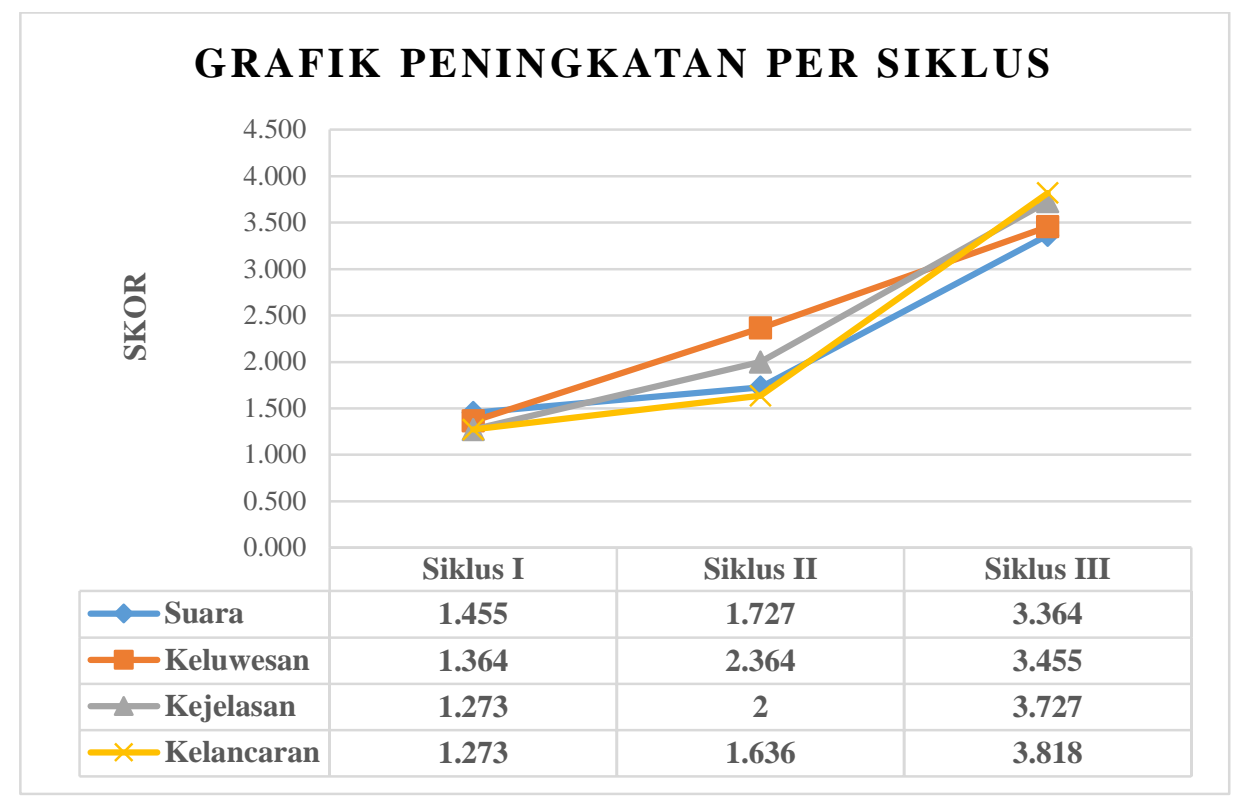

Berdasarkan hasil observasi proses dan penilaian di atas, tim peneliti melakukan refleksi atau pembahasan tentang langkah apa yang perlu diperbaiki dalam latihan komunikasi ini. Hasil refleksi sepakat bahwa mahasiswa agar serius berperan sebagai guru dan atau siswa. Pada siklus berikutnya, mahasiswa diminta menulis naskah yang akan disampaikan dan minta menghafalkan di rumah. Hasil refleksi ini digunakan untuk perencanaan latihan berikutnya.

Tinjauan kedua adalah latihan komunikasi nonverbal. Sesuai dengan refleksi pada siklus pertama, mahasiswa sebelum tampil diminta untuk merencanakan dan menghafalkan apa yang akan ditampilkan. Sedang keseriusan peran sebagai guru dan atau siswa selalu diingatkan oleh dosen pengampu pada setiap situasi yang terjadi. Keterampilan yang akan ditampilkan adalah memberi respon positif secara non verbal antara lain dalam bentuk mimik muka, gerakan tangan, menyentuh siswa, dan berjalan merata didalam kelas. Latihan ini dilakukan berulang-ulang sebanyak dua atau tiga kali secara langsung (sistem drill). Hasil penilaian pada kegiatan ini adalah seperti terlihat pada tabel di bawah ini.

Tabel 4. Penilaian Kegiatan Drill Dasar Komunikasi Non Verbal (Ditinjau pada siklus ketiga)

\begin{tabular}{cccccc}
\hline $\begin{array}{c}\text { No Urut } \\
\text { Mahasiswa }\end{array}$ & $\begin{array}{c}\text { Skor Keterampilan Komunikasi Non Verbal } \\
\text { Gerakan }\end{array}$ & Keluwesan & Kemenarikan & $\begin{array}{c}\text { Jumlah } \\
\text { Skor }\end{array}$ & $\begin{array}{c}\text { Rerata } \\
\text { Skor }\end{array}$ \\
\hline 1 & 2 & 2 & 2 & 6 & 2,0 \\
2 & 3 & 3 & 3 & 9 & 3,0 \\
3 & 3 & 3 & 2 & 8 & 2,7 \\
4 & 3 & 3 & 3 & 9 & 3,0 \\
5 & 3 & 3 & 2 & 8 & 2,7 \\
6 & 2 & 3 & 2 & 7 & 2,3 \\
7 & 3 & 2 & 2 & 7 & 2,3 \\
8 & 3 & 3 & 2 & 8 & 2,7 \\
9 & 3 & 2 & 3 & 8 & 2,7 \\
\hline
\end{tabular}




\begin{tabular}{cccccc}
\hline $\begin{array}{c}\text { No Urut } \\
\text { Mahasiswa }\end{array}$ & \multicolumn{2}{c}{ Skor Keterampilan Komunikasi Non Verbal } & Jumlah & Rerata \\
Gerakan & Keluwesan & Kemenarikan & Skor & Skor \\
\hline 10 & 2 & 3 & 3 & 8 & 2,7 \\
11 & 3 & 3 & 2 & 8 & 2,7 \\
Jumlah & 30 & 30 & 26 & & 7,8 \\
Rerata Skor & 2,7 & 2,7 & 2,4 & 7,8 & 2,6 \\
\hline
\end{tabular}

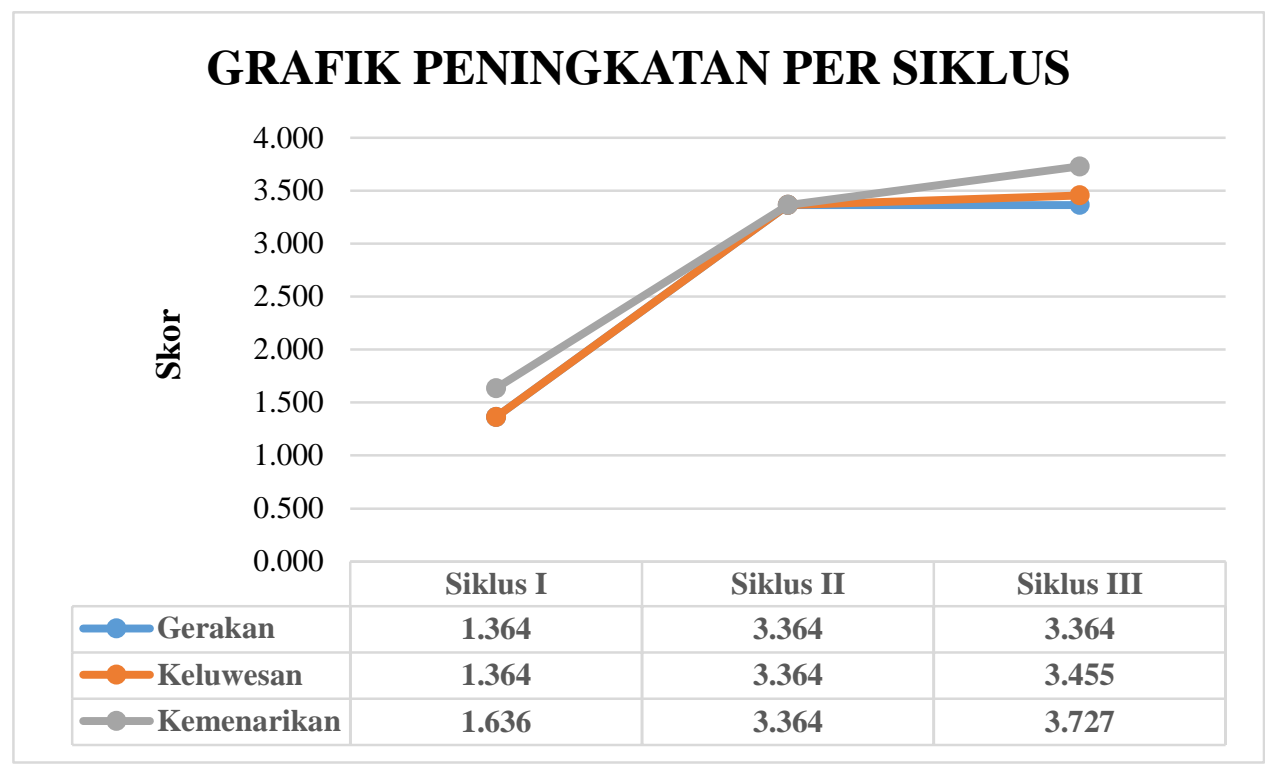

Hasil observasi kegiatan latihan ini menunjukan bahwa mahasiswa dalam tampil latihan lebih seriusan tetapi komunikasi nonverbal antar "siswa" dan "guru" belum begitu lancar. Pada penampilan awal, stimulus-respon diantara mereka kadang tidak sejalan, misalnya, "guru" akan menampilkan mimik muka senang kurang didukung oleh stimulus "siswa" yang merasa senang. Oleh karena itu, pada penampilan berikutnya "siswa" diminta untuk membantu memberi stimulus yang mendukung kemunculan komunikasi nonverbal.

Tinjauan ketiga dilaksanakan pada latihan keterampilan dasar mengajar terbatas tahap kedua. Latihan keterampilan dasar mengajar terbatas ini adalah lanjutan dari latihan sebelumnya (awal) yang dimaksudkan untuk mengetahui pengaruh latihan dasar komunikasi yang dilakukan sebelum kegiatan drill dasar komunikasi mengajar. Pertemuan tatap muka pertama pada kegiatan ini adalah latihan memberi penjelasan. Sebelum tampil, mahasiswa diharuskan membuat secara tertulis skenario yang akan dilaksanakan. Dosen pengampu sekaligus dosen peneliti ini mengamati proses latihan dengan mencocokan antara skenario yang ditulis dengan yang dilaksanakan. Apabila tidak sesuai maka, dosen pengampu langsung memberi tahu kesalahannya baik kesalahan substansi maupun kesalahan teknis. Hasil pengamatan proses latihan keterampilan dasar mengajar terbatas ini menunjukan bahwa penampilan mahasiswa nampak cukup luwes, cukup lancar dalam berkomunikasi, tetapi cara penjelasannya nampak monoton. Pertemuan tatap muka kedua pada kegiatan ini dengan materi latihan terbatas menggunakan media 
menunjukan bahwa penguasaan ragam media yang masih kurang, akan tetapi dari segi penampilan, mahasiswa nampak cukup luwes. Khusus penggunaan LCD mahasiswa masih perlu banyak belajar karena dari segi tampilan tulisan dan gambar kurang menarik.

Pertemuan tatap muka ketiga adalah latihan terbatas memimpin diskusi. Mahasiswa sebagai praktikan masih kurang dalam memimpin kegiatan diskusi. Diskusi sering terhenti karena "guru" tidak tahu

\section{SIMPULAN}

Berdasarkan hasil dan pembahasan dalam kajian ini dapat disimpulkan bahwa: (1) metode drill keterampilan dasar komunikasi verbal yang diterapkan pada praktik keterampilan dasar mengajar terbatas dalam pengajaran mikro dapat

\section{DAFTAR RUJUKAN}

Armai. (2013). Metode-Pembelajaran Drill.

Internet: http://www.kajianpustaka. com/2013/11/metode-pembelajarandrill.html

Castorina, Antonio Jose \& Gil Anton (1999).

The social knowledge psychogenesis and social representation. Journal Prospects. International Bureou Of Education. Vol XXIX. No 1.

Haryono, Hardjono, Budiyono, dan Yuli Utanto. (2015). Pengembangan model praktik mengajar reflektif: (upaya meningkatkan kompetensi pedagogik dan membentuk karakterpendidik bagaimana supaya "siswa" berpartisipasi. Dalam kondisi seperti ini, dosen pengampu memberi pengarahan bagaimana memimpin diskusi agar dapat berjalan lancar dan setiap peserta dapat berpartisipasi dalam diskusi. Kegiatan latihan oleh mahasiswa berikutnya berangsur-angsur relatif lebih baik seiring dengan pengertian bagaimana membimbing diskusi. Hasil observasi menunjukan bahwa komunikasi verbal dan non verbal mahasiswa mengalami kemajuan.

meningkatkan keterampilan dasar mengajar; dan (2) metode drill keterampilan dasar komunikasi nonverbal yang diterapkan pada praktik keterampilan dasar mengajar terbatas dalam pengajaran mikro dapat meningkatkan keterampilan dasar mengajar.

profesional mahasiswa PGSD). Prosiding LPPM UNY.

Muhammad Budyatna dan Leila Mona Ganiem. (2012). Teori Komunikasi antar pribadi. Cetakan ke-2. Jakarta: Kencana Perdana Media Group.

Muhammad Surya. (2013). Psikologi guru, konsep dan aplikasinya, dari guru, untuk guru. Bandung: Alfabeta.

Pratama, G. N. I. P., \& Triyono, M. B. (2015). Peningkatan kualitas pembelajaran prakarya dan kewirausahaan melalui metode CLTSMK. Jurnal Pendidikan Vokasi, 5(3), 313-324. 
Pratama, G. N. I. P. (2019, May). Basic communication skill drill in microteching context to improve the teching skills of civil engineering and planning education students, faculty of engineering, Yogyakarta State University. In IOP Conference Series: Materials Science and Engineering (Vol. 535, No. 1, p. 012014). IOP Publishing.

Sugiyanto (2016). Metode Drill. Internet: http://www.gudangteori.xyz/2016/0 1/pengertian-metode-drill-latihanmenurut. html

Suranto AW. (2011). Komunikasi interpersonal. Yogyakarta: Graha Ilmu

Toto Hernowo.Drill and Practice. Internet: http://totohernawo. blog.m3-access. com/ posts/35929_ DrillAndPractice.html.

Universitas Negeri Yogyakarta. (2013). Panduan pengajaran mikro, Yogyakarta: Unit Program Pengalaman Lapangan.

Wiyanthini Dewi, Ign. I Wayan Suwatra, \&I Wayan Romi Sudhit. (2015). Pengembangan media video pembelajaran keterampilan bertanya dan memberi penguatan pada matakuliah pengajaran mikro. $E$ Journal Edutech. Universitas Pendidikan Ganesha.Vol. 3 No: 1. 